\title{
Third-generation epidermal growth factor receptor tyrosine kinase inhibitors for the treatment of non-small cell lung cancer
}

\author{
Natalie M. Andrews Wright ${ }^{1}$, Glenwood D. Goss ${ }^{1,2}$ \\ ${ }^{1}$ The Ottawa Hospital Research Institute, Ottawa, Ontario, Canada; ${ }^{2}$ The University of Ottawa, Faculty of Medicine, Ottawa, Ontario, Canada \\ Contributions: (I) Conception and design: All authors; (II) Administrative support: None; (III) Provision of study materials or patients: None; (IV) \\ Collection and assembly of data: None; (V) Data analysis and interpretation: None; (VI) Manuscript writing: All authors; (VII) Final approval of \\ manuscript: All authors. \\ Correspondence to: Dr. Glenwood D. Goss, MD, FCPSA, FRCPC. 501 Smyth Rd, Box 944, Ottawa, Ontario, Canada. Email: ggoss@toh.ca.
}

\begin{abstract}
Mutations in the epidermal growth factor receptor $(E G F R)$ gene are the most common targetable genomic drivers of non-small cell lung cancer (NSCLC), occurring in approximately $50 \%$ and $10-15 \%$ of adenocarcinomas of the lung in Asian and Western populations, respectively. The most common EGFR-activating mutations, the exon 19 deletion and the L858R point mutation occurring in the receptor tyrosine kinase domain, are susceptible to inhibition. The first EGFR tyrosine kinase inhibitors (TKIs) to be evaluated were the reversible first-generation EGFR TKIs, gefitinib and erlotinib, followed by the irreversible second-generation EGFR TKIs, afatinib and dacomitinib. The study of acquired resistance mechanisms to first- and second-generation EGFR TKIs in patients with activating EGFR-mutated NSCLC identified the gatekeeper T790M point mutation, present in over $50 \%$ of cases, as the most common mechanism of acquired resistance. The need to overcome this resistance mechanism led to the development of third-generation EGFR TKIs, of which osimertinib is the only one to date with regulatory approval. In this review, we present the clinical context leading to the development of third-generation EGFR TKIs, the mode of action of these inhibitors and the clinical data supporting their use. We review third-generation TKI agents that are approved, in development, and those that failed in clinical trials. Finally, we will touch upon ongoing studies and future directions, such as combination treatment strategies, currently being explored to improve the efficacy of treatment with third-generation EGFR TKIs.
\end{abstract}

Keywords: Epidermal growth factor receptor $(E G F R)$; non-small cell lung cancer (NSCLC); protein kinase inhibitors; neoplasm drug resistance

Submitted Apr 09, 2019. Accepted for publication May 29, 2019.

doi: $10.21037 /$ tlcr.2019.06.01

View this article at: http://dx.doi.org/10.21037/tlcr.2019.06.01

\section{Introduction}

Lung cancer is the leading cause of cancer death globally (1). In North America and Western Europe, 50-70\% of nonsmall cell lung cancers (NSCLCs) are adenocarcinomas and therefore are the dominant subtype (2). The most common cause of lung cancer is tobacco exposure, but an important proportion of cases occur in never-smokers. While somatic oncogenic driver mutations (mutations in a gene which confer a selective growth advantage) occur in both smoking and non-smoking related tumours, they are more commonly found in tumours from non-smoking patients. These so called "oncogene addicted" tumours are dependent upon driver mutations to spur their development and maintain their malignant phenotype (3). Driver mutations have been identified in both adenocarcinoma and squamous carcinoma histologies but, to date, therapeutic success in targeting and inhibiting these drivers has been confined to drivers of adenocarcinomas.

Mutations in the epidermal growth factor receptor (EGFR) gene are among the most common genomic drivers of NSCLC, occurring in an estimated $50 \%$ of adenocarcinoma 
cases in Asia and in 10-15\% of adenocarcinomas in Western populations (4-6). As a percentage, these mutations are detected more commonly in tumours of never-smokers, females, patients of East Asian ethnicity and those with adenocarcinoma histology (6-8).

EGFR is a transmembrane receptor tyrosine kinase member of the ErbB family of receptors. Binding of a number of ligands, including epidermal growth factor (EGF), among others, causes receptor dimerization and triggers the activation of proliferative and cellsurvival signals $(9,10)$. EGFR protein overexpression in NSCLC was the basis for the development of gefitinib and erlotinib, two small molecule first-generation EGFR tyrosine kinase inhibitors (TKIs). Initially studied in unselected NSCLC populations, they were found to be most efficacious in patients whose tumours harboured activating somatic mutations in exons 18-21 of EGFR, with either small multi-nucleotide in-frame deletions in exon 19 (ex19del) or a point mutation in exon 21 , p.Leu858Arg (L858R), making up $90 \%$ of detected EGFR mutations $(5-7,11)$. In in vitro assays, these mutations were primarily heterozygous and compared to wild-type (WT) EGFR, demonstrated stronger and more prolonged signal activation, different tyrosine phosphorylation patterns and activation of primarily prosurvival pathways $(12,13)$.

Following the discovery of increased sensitivity to erlotinib and gefitinib in lung cancers harbouring activating $E G F R$ mutations, these agents quickly became the globally recommended treatment for EGFR mutationpositive NSCLC based on a number of pivotal phase III studies (14-17). Not surprisingly, given the genomic instability of cancers, tumours which are initially sensitive to oncogene inhibition may escape control via a number of resistance mechanisms. This led to the development and regulatory approval of second-generation irreversible EGFR inhibitors afatinib and dacomitinib $(18,19)$. In the first-line setting, first- and second-generation EGFR TKIs led to significant improvements in both objective response (range of $65 \%$ to $90 \%$ ) and progression-free survival (PFS) (range of 9 to 14.7 months) in NSCLC harbouring activating EGFR mutations (11,14-17,20-23), however resistance eventually develops in most patients [see article in this issue by Martinez-Marti et al. for a more detailed look at first-generation EGFR TKIs (24)].

\section{Necessity, the mother of invention-overcoming mechanisms of resistance to first- and second- generation EGFR TKIs}

A full description of the mechanisms of resistance to EGFR TKIs is beyond the scope of this review.

Multiple mechanisms of acquired resistance to firstand second-generation EGFR TKIs have been reported, including secondary EGFR mutations, bypass track signaling pathway activation (e.g., MET amplification) and histologic transformation (e.g., small-cell lung cancer or epithelial-tomesenchymal transition) $(25,26)$. Importantly in the context of third-generation EGFR TKIs, acquired resistance to gefitinib, erlotinib and afatinib has been associated with selection for a second EGFR mutation, the p.Thr790Met (T790M) point mutation in exon 20 (also in the kinase domain), detectable in $50-63 \%$ of tissue biopsy samples taken after disease progression $(25,27-31)$. The substitution of threonine for methionine at amino acid position 790 (T790M) in exon20 of EGFR translates to reduced binding of first-generation EGFR TKIs due to steric hindrance, which concomitantly restores ATP binding affinity similar to that of WT EGFR (32). First-generation EGFR TKIs have the disadvantage of being reversible inhibitors and are ineffective against the T790M mutation; while EGFR T790M only modestly affects gefitinib binding, gefitinib is outcompeted by ATP $(32,33)$. On the other hand, the second-generation afatinib has reasonable potency against dual L858R/T790M mutations, but cannot be delivered to patients in concentrations necessary to overcome T790M resistance, as seen in vitro $(33,34)$. The $\mathrm{IC}_{50}$ values of each agent from independent studies are summarized in Table 1. EGFR TKI specificity for mutant conformations is necessary for efficacy and to reduce toxicity caused by offtarget activity against WT EGFR.

In summary, erlotinib, gefitinib and afatinib are considered ineffective against T790M-mutant EGFR NSCLC. Consequently, "third-generation” EGFR TKIs were developed specifically to target the EGFR T790M mutation as the primary mechanism of acquired resistance to first- and second-generation EGFR inhibitors. In this review, we present the clinical context leading to the development of third-generation EGFR TKIs, the mode of action of these inhibitors and the clinical data to date supporting their use. We review the third-generation TKI agents that are 
Table 1 Summary of reported pre-clinical half maximal inhibitory concentrations $\left(\mathrm{IC}_{50}\right)$ of third-generation EGFR TKIs for common EGFR mutations

\begin{tabular}{|c|c|c|c|c|c|c|c|c|}
\hline EGFR TKIs & Agents & \multicolumn{7}{|c|}{ Alterations in EGFR } \\
\hline \multirow[t]{3}{*}{ Osimertinib } & AZD9291 & & $12 \mathrm{nM}^{\star \ddagger}$ & $1 \mathrm{nM}^{\star \ddagger}$ & & $184 \mathrm{nM}^{\star \ddagger}$ & & (33) \\
\hline & & $56 \mathrm{nM}^{\mathrm{B1}}$ & $36 \mathrm{nM}^{\mathrm{c}}$ & $15 \mathrm{nM}^{\mathrm{D} 1}$ & $13 \mathrm{nM}^{\mathrm{E} 1}$ & $152 \mathrm{nM}^{\mathrm{F} 1}$ & & (35) \\
\hline & & $41 \mathrm{nM}^{\mathrm{B} 1}$ & $26 \mathrm{nM}^{\mathrm{C}}$ & $31 \mathrm{nM}^{\mathrm{D} 1}$ & $41 \mathrm{nM}^{\mathrm{E} 2}$ & & & (36) \\
\hline Nazartinib & EGF816 & $66 \mathrm{nM}^{\mathrm{A}}$ & $35 \mathrm{nM}^{\mathrm{A}}$ & $5.1 \mathrm{nM}^{\mathrm{A}}$ & $52 \mathrm{nM}^{\mathrm{A}}$ & $1,031 \mathrm{nM}^{\mathrm{A}}$ & & (37) \\
\hline Mavelertinib & PF-06747775 & $5 \mathrm{nM}^{\mathrm{B1}}$ & $4 \mathrm{nM}^{\mathrm{C}}$ & $12 \mathrm{nM}^{\mathrm{D} 1}$ & $3 \mathrm{nM}^{\mathrm{E} 1}$ & $307 \mathrm{nM}^{\mathrm{F} 1}$ & & (35) \\
\hline Avitinib & AC0010 & $10.4 \mathrm{nM}^{\mathrm{B} 2}$ & & $\begin{array}{r}0.18 \mathrm{nM}^{\ddagger} \\
7.3 \mathrm{nM}^{\mathrm{D} 1} \\
\text { and } 2.8 \mathrm{nM}^{\mathrm{D} 2}\end{array}$ & & $\begin{array}{l}7.68 \mathrm{nM}^{\ddagger} \\
837 \mathrm{nM}^{\mathrm{F3}}\end{array}$ & $\begin{array}{l}\text { Kinase and cell-based } \\
\text { assays are reported }\end{array}$ & $(38)$ \\
\hline Naquotinib & ASP8273 & $\begin{array}{c}11 \mathrm{nM}^{\mathrm{B} 1} \\
9 \mathrm{nM}^{\mathrm{A}}\end{array}$ & $\begin{array}{l}1.3 \mathrm{nM}^{\mathrm{C}} \\
11 \mathrm{nM}^{\mathrm{A}}\end{array}$ & $\begin{array}{l}6 \mathrm{nM}^{\mathrm{D} 1} \\
9 \mathrm{nM}^{\mathrm{A}}\end{array}$ & $\begin{array}{c}5 \mathrm{nM}^{\mathrm{E} 2} \\
10 \mathrm{nM}^{\mathrm{A}}\end{array}$ & $830 \mathrm{nM}^{\mathrm{A}}$ & $\begin{array}{c}\text { Kinase and cell-based } \\
\text { assays are reported. See } \\
\text { publication for } \mathrm{Ba} / \mathrm{F} 3 \text { cell- } \\
\text { based assay results with } \\
\text { other EGFR TKIs }\end{array}$ & (36) \\
\hline Olmutinib & HM61713 & $9.2 \mathrm{nM}^{\mathrm{B} 2}$ & & $10 \mathrm{nM}^{\mathrm{D} 1}$ & & $2,225 \mathrm{nM}^{\mathrm{F2}}$ & & $(40)$ \\
\hline Rociletinib & CO-1686 & $79 \mathrm{nM}^{\mathrm{B} 1}$ & $46 \mathrm{nM}^{\mathrm{C}}$ & $16 \mathrm{nM}^{\mathrm{D} 1}$ & $9 \mathrm{nM}^{\mathrm{E} 1}$ & $1598 \mathrm{nM}^{\mathrm{F} 1}$ & & (35) \\
\hline \multirow[t]{4}{*}{ Afatinib } & - & & $<1 \mathrm{nM}^{\star \ddagger}$ & $3 \mathrm{nM}^{\star \ddagger}$ & & $3 \mathrm{nM}^{\star \ddagger}$ & & (33) \\
\hline & & $2 \mathrm{nM}^{\mathrm{B1}}$ & $0.08 \mathrm{nM}^{\mathrm{C}}$ & $121 \mathrm{nM}^{\mathrm{D1}}$ & $279 \mathrm{nM}^{\mathrm{E} 2}$ & & & (36) \\
\hline & & $0.6 \mathrm{nM}^{\mathrm{A}}$ & $0.6 \mathrm{nM}^{\mathrm{A}}$ & $179 \mathrm{nM}^{\mathrm{A}}$ & $146 \mathrm{nM}^{\mathrm{A}}$ & $30 \mathrm{nM}^{\mathrm{A}}$ & & $(37)$ \\
\hline & & $1.8 \mathrm{nM}^{\mathrm{B} 2}$ & & $53 \mathrm{nM}^{\mathrm{D} 1}$ & & $31 \mathrm{nM}^{\mathrm{F} 2}$ & & (40) \\
\hline Dacomitinib & - & & $<1 \mathrm{nM}^{\star \ddagger}$ & $10 \mathrm{nM}^{\star \ddagger}$ & & $3 \mathrm{nM}^{\star \ddagger}$ & & (33) \\
\hline
\end{tabular}

${ }^{*}$, reported apparent $\mathrm{IC}_{50}$, due to time-dependent changes to enzyme activity with irreversible inhibitors; ${ }^{\ddagger}$, assessed by kinase assay (see methods and supplemental methods from: $(32,37,38)$; ${ }^{\text {, }}$, evaluated in Ba/F3 cells transduced with either mutated or wild-type EGFR, see (35,36,38); ${ }^{\text {, }}$ Exon 19 deletion evaluated in PC-9 cells $\left({ }^{B 1}\right)$ and HCC827 cells $\left({ }^{B 2}\right) ;{ }^{C}$, L858R mutation evaluated in H3255 cells $\left({ }^{\circ}\right) ;{ }^{D}$, L858R/ T790M mutation evaluated in H1975 cells $\left({ }^{\mathrm{D} 1}\right)$ and NIH/3T3_TC32T8 cells $\left({ }^{\mathrm{D} 2}\right)$; ${ }^{\mathrm{E}}$, Ex19del/T790M evaluated in PC9-DRH cells $\left({ }^{\mathrm{E} 1}\right)$ and PC9ER cells $\left({ }^{E 2}\right)$; ${ }^{F}$, WT EGFR evaluated in A549 cells $\left({ }^{F 1}\right), H 358$ cells $\left({ }^{F 2}\right)$ and A431 $\left({ }^{F 3}\right)$. EGFR, epidermal growth factor receptor; TKI, tyrosine kinase inhibitor; WT, wild-type. 
approved, in development, and those that failed in clinical trials. Finally, we will touch upon combination treatment strategies currently being explored to improve the efficacy of treatment with third-generation EGFR TKIs.

\section{Third-generation EGFR TKIs-targeting the T790M mutation}

The development of the third-generation EGFR TKIs focused on three key aspects namely; the inhibition of T790M isoform-specific kinase activity, maintaining efficacy against exon 19 and 21 mutations, and sparing the inhibition of WT EGFR (33). The first third-generation EGFR TKI to be developed was WZ4002 (41), which did not progress into clinical trials, followed by rociletinib (CO-1686) (42) and osimertinib (AZD9291) (33). All three are reported to be potent inhibitors of T790M-mutant EGFR, while exhibiting minimal activity against the WT receptor. A common feature of these inhibitors is the covalent bond they form with the C797 residue within the EGFR ATP-binding pocket $(33,42)$. A selected summary of ongoing clinical trials with third-generation EGFR inhibitors is found in Table 2. Multiple third-generation agents have now been developed but, to date the only one with regulatory approval is osimertinib. Therefore, the majority of this review focuses on osimertinib, though others will be mentioned. Figure 1 illustrates the clinical development status of third-generation EGFR TKIs under investigation in NSCLC.

\section{Osimertinib (AZD9291)}

Osimertinib (AZD9291) is an irreversible EGFR TKI selective for both EGFR-TKI sensitizing and T790M resistance mutations (33) and has a nearly $200 \times$ greater potency against L858R/T790M than against WT-EGFR. Osimertinib was the first third-generation EGFR TKI to receive FDA and EMA approval for the treatment of metastatic EGFR-mutant and acquired EGFR T790M mutation-positive NSCLC progressing on or after EGFR TKI therapy $(50,51)$.

\section{Osimertinib in EGFR-TKI (first- and second-generation) resistant NSCLC}

The initial phase I/II AURA (NCT01802632) study was the first to report use of osimertinib in patients with EGFRmutant (either ex19del, L858R or T790M) advanced lung cancer who had radiological disease progression after previous treatment with an EGFR TKI (52). This 253-patient study documented a favourable adverse event (AE) profile and encouraging clinical benefit. Jänne and colleagues initially reported an overall objective tumour response of $51 \%$. However, in the 127 patients with a centrally confirmed EGFR T790M tumour mutation who could be evaluated for response, the objective response was $61 \%$ (95\% CI, $52 \%$ to $70 \%$ ), compared to a response of $21 \%$ (95\% CI, $12 \%$ to $34 \%$ ) in the 61 patients without a detectable T790M mutation. The median PFS was also higher in EGFR T790M-mutant patients compared to those without a detected tumour mutation, 9.6 months (95\% CI, 8.3 to not reached) vs. 2.8 months ( $95 \%$ CI, 2.1 to 4.3 ) respectively. The most common AEs were diarrhea (47\%), skin toxicity (rash/acne, $40 \%$ ), nausea (22\%) and decreased appetite $(21 \%)$. The $80 \mathrm{mg}$ daily dose was selected as the recommended phase II dose (RP2D). In an updated analysis of phase I data from the 61 response-evaluable patients harbouring the T790M tumour mutation treated at the RP2D of $80 \mathrm{mg}$ daily of osimertinib, the objective response was $71 \%$ (95\% CI, $57 \%$ to $82 \%$ ) and median PFS was 9.7 months (95\% CI, 8.3 to 13.6 ) (53).

Based on these encouraging results, the phase II portion of the AURA study was extended to include an additional 201 T790M-positive advanced NSCLC patients, dosed at $80 \mathrm{mg}$ daily (54). In 198 evaluable patients, the primary endpoint of overall response was $62 \%$ (95\% CI, 54\% to $68 \%$ ) with a disease control rate of $90 \%$ (95\% CI, $85 \%$ to $94 \%$ ) and a median PFS of 12.3 months (95\% CI, 9.5 to 13.8). These results confirmed initial observations of clinical efficacy. Diarrhea and rash were the most common possibly causally related AEs. Interstitial lung disease (ILD) was reported in eight patients of 201, and was fatal in three cases.

Whilst enrolling to AURA extension the AURA 2 study was initiated. The AURA2 study, an open-label, single arm, phase II study (NCT02094261), enrolled patients with confirmed EGFR T790M-positive mutations, locally advanced or metastatic (stage IIIB/IV) NSCLC who progressed on previous EGFR TKI therapy to receive osimertinib $80 \mathrm{mg}$ orally once daily (55). The primary endpoint was the objective response rate, and at data cut-off, objective response was seen in 140 (70\%; 95\% CI, 64\% to $77 \%$ ) of the 199 evaluable patients by blinded independent central review. Confirmed complete responses were achieved in $6(3 \%)$ patients and partial responses were achieved in $134(67 \%)$ patients. In the context of EGFR TKI-resistant disease, this was an impressive and exciting response. 
Table 2 Selected ongoing clinical trials with third-generation (T790M-targeting) EGFR TKIs* in NSCLC

\begin{tabular}{|c|c|c|c|c|c|}
\hline Agent & $\begin{array}{l}\text { Phase/Alt. study } \\
\text { name }\end{array}$ & $\begin{array}{l}\text { Monotherapy or } \\
\text { combination }\end{array}$ & Clinical conditions (line, mutation status etc.) & $\begin{array}{l}\text { Clinical trial ID/ } \\
\text { reference }\end{array}$ & Comments \\
\hline \multirow[t]{15}{*}{ AZD9291 } & Phase 3 ADAURA & Osimertinib & $\begin{array}{l}\text { Stage IB-IIIA EGFRm+ (Ex19Del, L858R) } \\
\text { NSCLC, following complete tumour resection } \\
\pm \text { adjuvant chemotherapy }\end{array}$ & NCT02511106/(43) & $\begin{array}{l}\text { Active, not } \\
\text { recruiting }\end{array}$ \\
\hline & Phase 2 & Osimertinib & $\begin{array}{l}\text { Stage IIIB-IV or Recurrent NSCLC, EGFRm+ } \\
\text { (Exon } 20 \text { Insertion) }\end{array}$ & NCT03191149 & Recruiting \\
\hline & Phase 1 & $\begin{array}{l}\text { Osimertinib and } \\
\text { dacomitinib }\end{array}$ & TKI-naïve metastatic EGFRm+ NSCLC & NCT03810807 & Recruiting \\
\hline & Phase 1 TATTON & $\begin{array}{l}\text { Osimertinib and } \\
\text { AZD6094 (savolitinib) or } \\
\text { selumetinib }\end{array}$ & $\begin{array}{l}\text { EGFRm+ Advanced NSCLC with progression } \\
\text { following EGFR TKI therapy }\end{array}$ & NCT02143466/(44) & Recruiting \\
\hline & Phase $1 / 2$ & $\begin{array}{l}\text { Osimertinib and } \\
\text { bevacizumab }\end{array}$ & Patients with EGFRm+ NSCLC & NCT02803203/(45) & $\begin{array}{l}\text { Active, not } \\
\text { recruiting }\end{array}$ \\
\hline & $\begin{array}{l}\text { Phase } 2 \\
\text { BOOSTER }\end{array}$ & $\begin{array}{l}\text { Osimertinib and } \\
\text { bevacizumab }\end{array}$ & $\begin{array}{l}\text { 2nd line, stage Illb-IVb NSCLC, EGFRm+ } \\
\text { (Ex19del or L858R, and T790M) }\end{array}$ & NCT03133546 & Recruiting \\
\hline & Phase 2 & $\begin{array}{l}\text { Osimertinib and } \\
\text { bevacizumab }\end{array}$ & $\begin{array}{l}\text { EGFRm+ (activating and T790M) NSCLC and } \\
\text { brain metastases, post-progression on first- } \\
\text { or second-generation EGFR TKI }\end{array}$ & NCT02971501 & Recruiting \\
\hline & Phase 2 & $\begin{array}{l}\text { Osimertinib and } \\
\text { ramucirumab }\end{array}$ & $\begin{array}{l}\text { Advanced or metastatic EGFRm+ NSCLC, } \\
\text { TKI-naïve }\end{array}$ & NCT03909334 & $\begin{array}{l}\text { Not yet } \\
\text { recruiting }\end{array}$ \\
\hline & Phase $1 / 2$ & $\begin{array}{l}\text { Osimertinib and itacitinib } \\
\text { (JAK1 inhibitor) }\end{array}$ & $\begin{array}{l}\text { EGFRm+ advanced or metastatic NSCLC, } \\
\text { no more than one prior line of therapy }\end{array}$ & NCT02917993 & Recruiting \\
\hline & $\begin{array}{l}\text { Phase } 2 \text { TAKUMI } \\
\text { (LOGIK1604/ } \\
\text { NEJ032A) }\end{array}$ & $\begin{array}{l}\text { Osimertinib }+/- \\
\text { carboplatin/pemetrexed }\end{array}$ & $\begin{array}{l}\text { EGFRm+ }(\text { T790M) advanced/metastatic } \\
\text { NSCLC, progressed on previous EGFR-TKI }\end{array}$ & $\begin{array}{l}\text { UMIN000024438/ } \\
\qquad(46)\end{array}$ & Recruiting \\
\hline & Phase 1 & $\begin{array}{l}\text { Osimertinib, platinum } \\
\text { and etoposide }\end{array}$ & $\begin{array}{l}\text { Metastatic EGFRm+ lung cancer with } \\
\text { concurrent RB1 and TP53 alterations }\end{array}$ & NCT03567642 & Recruiting \\
\hline & Phase $1 b$ & $\begin{array}{l}\text { Osimertinib and navitoclax } \\
\text { (BCL-2 inhibitor) }\end{array}$ & $\begin{array}{l}\text { EGFRm+ advanced or metastatic NSCLC } \\
\text { following resistance to initial EGFR TKI }\end{array}$ & NCT02520778 & Recruiting \\
\hline & Phase 2 & Osimertinib and T-DM1 & $\begin{array}{l}\text { Advanced EGFRm+ NSCLC with HER2 } \\
\text { bypass track resistance }\end{array}$ & NCT03784599 & Recruiting \\
\hline & Phase 2 OUTRUN & $\begin{array}{l}\text { Osimertinib with } \\
\text { stereotactic radiosurgery }\end{array}$ & EGFRm+ NSCLC with brain metastases & NCT03497767 & $\begin{array}{l}\text { Not yet } \\
\text { recruiting }\end{array}$ \\
\hline & Phase 3 LAURA & $\begin{array}{l}\text { Osimertinib with radiation } \\
\text { therapy }\end{array}$ & $\begin{array}{l}\text { maintenance post definitive platinum-based } \\
\text { chemoradiation, stage III unresectable NSCLC }\end{array}$ & NCT03521154 & Recruiting \\
\hline
\end{tabular}

Table 2 (continued) 
Table 2 (continued)

\begin{tabular}{|c|c|c|c|c|c|}
\hline Agent & $\begin{array}{l}\text { Phase/Alt. study } \\
\text { name }\end{array}$ & $\begin{array}{l}\text { Monotherapy or } \\
\text { combination }\end{array}$ & Clinical conditions (line, mutation status etc.) & $\begin{array}{l}\text { Clinical trial ID/ } \\
\text { reference }\end{array}$ & Comments \\
\hline \multirow[t]{5}{*}{ EGF816 } & $\begin{array}{c}\text { Phase 1/2 } \\
\text { CEGF816X2101 }\end{array}$ & Monotherapy & $\mathrm{EGFRm}+\mathrm{NSCLC}$ & NCT02108964/(47) & $\begin{array}{l}\text { Active, not } \\
\text { recruiting }\end{array}$ \\
\hline & Phase 2 & EGF816 and gefitinib & TKI-naïve EGFRm+ NSCLC & NCT0329213 & Recruiting \\
\hline & $\begin{array}{c}\text { Phase } 2 \\
\text { CEGF816X2201C }\end{array}$ & EGF816 and nivolumab & Previously treated EGFRm+ (T790M) NSCLC & NCT02323126 & Recruiting \\
\hline & $\begin{array}{c}\text { Phase } 1 / 2 \\
\text { CINC280X2105C }\end{array}$ & $\begin{array}{l}\text { EGF816 and C-MET } \\
\text { inhibitor (INC280) }\end{array}$ & Advanced EGFRm+ NSCLC (many groups) & NCT02335944 & Recruiting \\
\hline & Phase 1 & $\begin{array}{l}\text { PDR001 with EGF816 } \\
\text { (and other agents) }\end{array}$ & NSCLC, cannot be EGFR-mutant & NCT02900664 & Recruiting \\
\hline \multirow[t]{4}{*}{ AC0010 } & Phase 1 & AC0010 & $\begin{array}{l}\text { Previously treated NSCLC patients with } \\
\text { EGFRm }+(T 790 M)\end{array}$ & NCT02330367/(48) & $\begin{array}{l}\text { Active, not } \\
\text { recruiting }\end{array}$ \\
\hline & Phase 1 & AC0010MA & $\begin{array}{l}\text { Locally advanced or metastatic NSCLC. } \\
\text { EGFRm+ (activating or T790M) }\end{array}$ & NCT02448251 & Recruiting \\
\hline & Phase 2 & AC0010 & $\begin{array}{l}\text { EGFRm+ (T790M), advanced NSCLC } \\
\text { (expanded sample size at RP2D) }\end{array}$ & NCT03300115 & Recruiting \\
\hline & Phase 2 TRUMP & Avitinib maleate & de novo T790m EGFR mutation & NCT03574402 & $\begin{array}{l}\text { Not yet } \\
\text { recruiting }\end{array}$ \\
\hline $\begin{array}{l}\text { PF- } \\
06747775\end{array}$ & Phase 2 & $\begin{array}{l}\text { Monotherapy PF- } \\
\text { 06747775, and with } \\
\text { palbociclib or avelumab }\end{array}$ & $\begin{array}{l}\text { EGFRm+ (ex19del or L858R +/- T790M) } \\
\text { NSCLC }\end{array}$ & NCT02349633/(49) & $\begin{array}{l}\text { Active, not } \\
\text { recruiting }\end{array}$ \\
\hline
\end{tabular}

*, CO-1686, HM61713 and ASP8273 excluded due to halted drug development. Clinicaltrials.gov search terms included: "AZD9291" (86 studies), "AC0010" (4 studies), "avitinib” (1 study), "EGF816” (7 studies), "nazartinib” (0 studies), "PF-06747775” (1 study), "mavelertinib” (0 studies), "YH25448" ( 1 study), "GNS-1480" (0 studies) in combination with "NSCLC" that were "not yet recruiting", "recruiting" or "active, not recruiting". Data current as of 10-Apr-2019. Alt., alternative; EGFRm+, EGFR mutation-positive; NSCLC, non-small cell lung cancer; CNS, central nervous system; RP2D, recommended phase II dose.

A pre-planned pooled analysis of T790M-positive patients from the AURA extension and AURA2 studies enabled evaluation of 411 patients previously treated with EGFR inhibitors (first- or second-generation) (56). In the evaluable for response set, the pooled objective response was $66 \%$ (95\% CI, $61 \%$ to $70 \%$ ) and the median PFS (full analysis set), 9.9 months (95\% CI, 9.5 to 12.3 ). The pooled median overall survival (OS) was 26.8 months (95\% CI, 24.2 to not calculable (NC)]; median OS in the secondline and third-line (or greater) cohorts was 25.8 months (95\% CI, 24.0 to NC) and NC (95\% CI, 22.1 to NC), respectively. The 12 - and 24 -month survival rates were
$80 \%$ and $56 \%$, respectively. The AEs were consistent with previous reports.

This led to AURA3 (NCT02151981), the confirmatory phase III study of osimertinib compared to platinum-based chemotherapy plus pemetrexed, published in 2017 (57). This was a randomized (2:1, 419 patients), open-label trial in the second-line setting for patients with centrallyconfirmed EGFR T790M mutation-positive advanced NSCLC who progressed while on first-line EGFR TKI therapy. The primary endpoint of median PFS was met, with a significantly longer median PFS with osimertinib than with chemotherapy [10.1 vs. 4.4 months; hazard ratio 


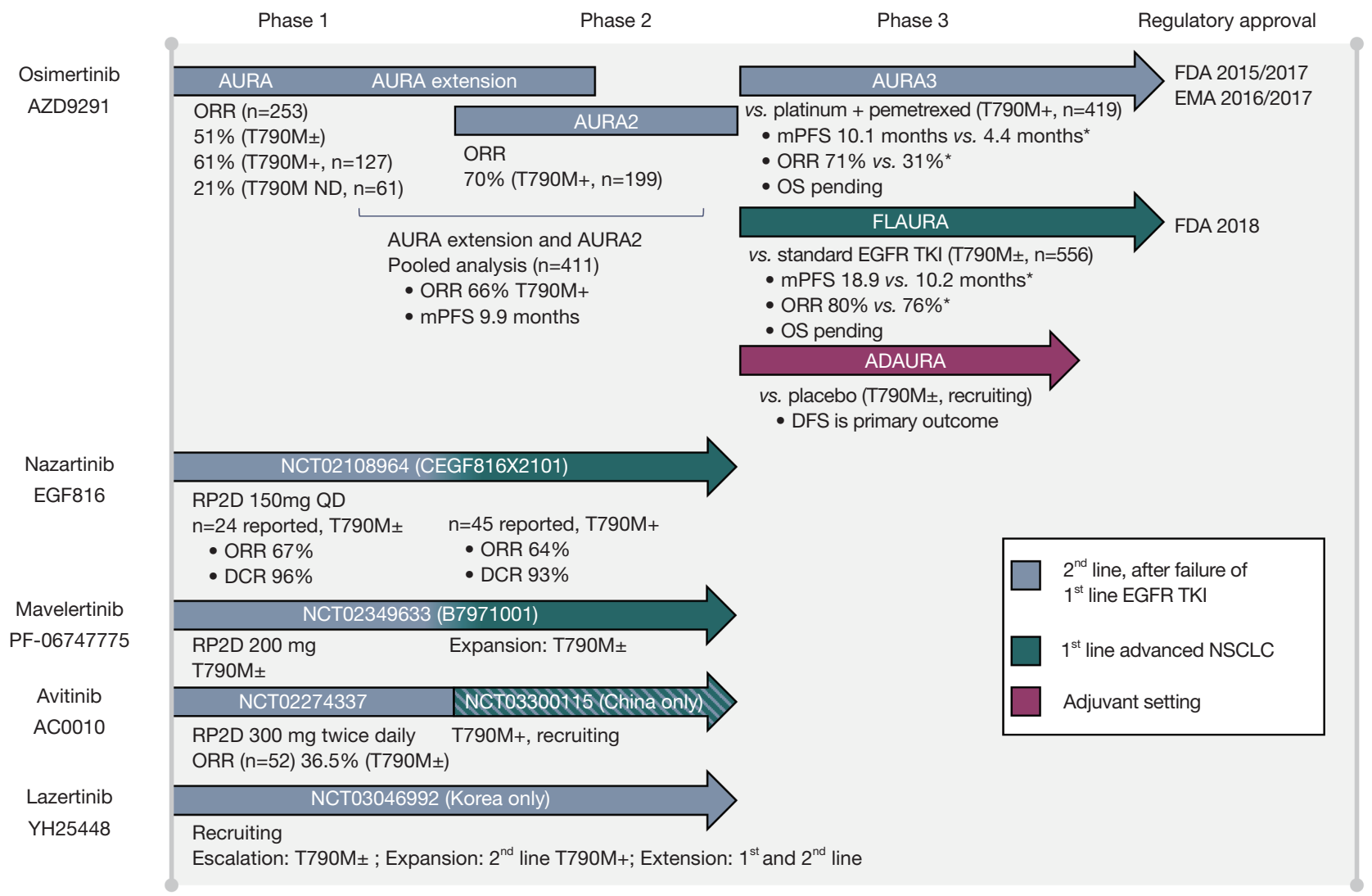

Figure 1 Summary of third-generation EGFR TKI monotherapy clinical development in EGFR mutation-positive NSCLC. All clinical trials included in this figure required, at minimum, for tumours to have an activating EGFR mutation (EGFRm+ = ex19del/L858R), T790M mutations were not always inclusion criteria, and the requirement for T790M status is indicated as follows: T790M+ (required T790M mutation), $\mathrm{T} 790 \mathrm{M} \pm$ (accepted patients regardless of T790M mutation status) or T790M ND (T790M mutation not detected). DCR, disease control rate; EGFR, epidermal growth factor receptor; mPFS, median progression-free survival; ORR, objective response rate; OS, overall survival; RP2D, recommended phase 2 dose; TKI, tyrosine kinase inhibitor. Asterix (*) indicates values belonging to the comparator arm. Agents for which the clinical development has been ceased (rociletinib, olmutinib and naquotinib) are not included. Data current as of 29Mar-2019.

(HR), 0.30; 95\% CI, 0.23 to $0.41 ; \mathrm{P}<0.001]$. The objective response was also significantly better with osimertinib $(71 \%$; $95 \%$ CI, $65 \%$ to $76 \%$ ) than with chemotherapy (31\%; $95 \%$ CI, $24 \%$ to $40 \%$ ). Importantly, the toxicity profile was more favourable in the osimertinib arm than in the platinumpemetrexed arm. These trial results solidified osimertinib's place as standard treatment in EGFR T790M-positive NSCLC patients after disease progression on a first- or second-generation EGFR TKI. Data on OS are not yet mature, but are eagerly anticipated.

\section{Osimertinib as a fist-line therapy}

Given the known activity of osimertinib against ex19del and L858R alterations (33), the next step was to examine its efficacy in the first-line setting testing two hypotheses; firstly, whether the activity of osimertinib against the common sensitizing mutations was as robust as the first- and second-generation EGFR TKIs and secondly, whether treating with a T790M inhibitor could delay the development of T790M mutations. In the FLAURA study (NCT02296125), osimertinib was compared to standard EGFR-TKIs in previously untreated, EGFR mutationpositive advanced NSCLC (58). This was a double-blind, randomized phase III trial, enrolling 556 patients with $E G F R$ mutation-positive (ex19del or L858R) advanced NSCLC to either gefitinib or erlotinib $v s$. osimertinib at a 1:1 ratio. The primary endpoint was investigator- 
assessed PFS. Median PFS was significantly longer with osimertinib than with standard EGFR-TKIs (18.9 vs. 10.2 months; HR for disease progression or death, 0.46; $95 \% \mathrm{CI}, 0.37$ to $0.57 ; \mathrm{P}<0.001)$. The objective response was similar in both groups: $80 \%$ with osimertinib and $76 \%$ with standard EGFR-TKIs but the median duration of response was longer with osimertinib versus standard EGFR-TKIs [17.2 months (95\% CI, 13.8 to 22.0 ) and 8.5 months (95\% CI, 7.3 to 9.8), respectively]. A doubling of the duration of response with osimertinib suggests it is effective at delaying the onset of acquired resistance in comparison to erlotinib or gefitinib. Furthermore, the osimertinib arm had less frequent AEs of grade 3 or higher. Though survival data is not yet mature, the FDA granted osimertinib approval for first-line treatment of metastatic NSCLC with exon 19 deletions or exon 21 L858R mutations based on the FLAURA data (59).

\section{Adjuvant therapy with osimertinib}

Adjuvant therapy with EGFR TKIs versus placebo was originally examined with first-generation EGFR TKIs in the BR19 (gefitinib) and RADIANT (erlotinib) studies $(60,61)$, which were conducted in unselected NSCLC populations, as these trials were initiated when the importance of EGFR mutations was not thoroughly understood. Both studies had small numbers of EGFR tumour mutation-positive patients (BR19 n=15, RADIANT n=161). In RADIANT, EGFR mutation-positive patients receiving erlotinib trended towards improved disease-free survival, however this did not reach statistical significance. In the BR19 study the EGFR mutation-positive sample size precluded meaningful benefit analysis, neither disease-free survival or OS were improved in this population. More recently in EGFR-mutant (Ex19del/ L858R) NSCLC, a Chinese study of gefitinib versus vinorelbine plus cisplatin in the adjuvant setting reported a significantly longer median disease-free survival with gefitinib [28.7 months (95\% CI, 24.9 to 32.5)] than with vinorelbine plus cisplatin [18.0 months (95\% CI, 13.6 to 22.3); HR 0.60; 95\% CI, 0.42 to $0.87 ; \mathrm{P}=0.0054]$ (62).

With this as background, the ongoing ADAURA (NCT02511106) is currently investigating the implementation of osimertinib therapy in the adjuvant setting (see Table 2) (43). ADAURA is a phase III, double-blind, randomized study of osimertinib versus placebo in primary non-squamous stage IB-IIIA NSCLC, following complete tumour resection, with or without adjuvant chemotherapy. Patients are required to have central confirmation of an EGFR ex19del or L858R mutation and are randomized 1:1 to receive osimertinib $80 \mathrm{mg}$ once daily or placebo once daily. The primary endpoint of this study is disease-free survival and results are expected in 2021.

\section{Osimertinib in lung cancer central nervous system (CNS) metastases}

CNS metastases are more common in EGFR-mutant NSCLC than in EGFR WT patients (63) and a number of small prospective trials, subgroup analyses and case studies have documented limited CNS efficacy with EGFR TKIs. Response rates in patients with brain metastases are $0-33 \%$ with gefitinib, $58.3-83 \%$ with erlotinib and $35-82 \%$ with afatinib (64-69). Improvements in overall PFS with afatinib from the LUX-lung 3 and 6 studies were detected even in patients with brain metastases (64). With this background, we discuss below the role of osimertinib in EGFR mutationpositive NSCLC with CNS metastases.

The first indications of intra-cranial osimertinib activity were detected in the AURA extension study which included 25 patients in a CNS response analysis set. Encouraging systemic PFS with osimertinib in patients with CNS metastases and a high CNS response (64\%; 95\% CI, $43 \%$ to $82 \%)$ in those with measurable CNS lesions $(\mathrm{n}=25)$ was reported. Four patients experienced a complete response, 12 patients a partial response and tumour shrinkage was seen in the majority of patients (54). Similarly, the high proportion of objective responses observed with osimertinib in patients with CNS metastases from the AURA2 study $(\mathrm{n}=84)$ was consistent across pre-defined subgroups, and in a post-hoc analysis of PFS in sub-groups (55).

In 2018, Goss et al. published a pre-specified sub-group analysis of pooled data from the AURA extension and AURA2 studies (70). Of 128 patients with CNS metastases on baseline brain scans, 50 were included in the evaluable CNS response set. Confirmed CNS objective response and disease control rates were $54 \%(27 / 50 ; 95 \%$ CI, 39\% to $68 \%$ ) and $92 \%$ (46/50; $95 \%$ CI, $81 \%$ to $98 \%)$, respectively and CNS response was observed regardless of prior brain radiotherapy. The safety profile observed in the evaluable CNS response set was consistent with the overall patient population.

Due to encouraging signal in the phase II studies, the AURA3 study pre-planned a CNS disease subgroup analysis (71), finding that of the 116 patients with measurable or non-measurable CNS metastases, the CNS overall response in patients with $\geq 1$ measurable CNS lesions 
$(\mathrm{n}=46)$ was $70 \%$ (21 of $30 ; 95 \%$ CI, $51 \%$ to $85 \%)$ with osimertinib and $31 \%$ (5 of $16 ; 95 \%$ CI, $11 \%$ to $59 \%$ ) with platinum-pemetrexed (odds ratio, 5.13; 95\% CI, 1.44 to 20.64; $\mathrm{P}=0.015$ ) and the response was $40 \%$ (30 of $75 ; 95 \%$ CI, $29 \%$ to $52 \%$ ) and $17 \%$ (7 of $41 ; 95 \%$ CI, $7 \%$ to $32 \%$ ), respectively, in the full analysis set $(n=116)$ (odds ratio, 3.24; 95\% CI, 1.33 to $8.81 ; \mathrm{P}=0.014$ ).

Along with preclinical data supporting the ability of osimertinib to cross the blood-brain barrier and penetrate the CNS (72), phase II observations led to a pre-planned sub-group analysis, with CNS PFS as the primary objective, in patients with CNS metastases evaluable-for-response in the FLAURA study $(n=41$, osimertinib $n=22$, standard EGFR TKI n=19) (73). Median CNS PFS in patients with measurable and/or non-measurable CNS lesions was not reached with osimertinib (95\% CI, 16.5 months to NC) and 13.9 months (95\% CI, 8.3 months to NC) with standard EGFR-TKIs (HR, 0.48; 95\% CI, 0.26 to 0.86 ; $\mathrm{P}=0.014$ ). This analysis confirmed the probability of experiencing a CNS progression event was consistently lower with osimertinib versus standard EGFR-TKIs, thus confirming that osimertinib has CNS efficacy in patients with untreated EGFR-mutated NSCLC.

\section{Other third-generation EGFR TKIs}

\section{Rociletinib (CO-1686)}

Rociletinib is an oral, targeted covalent (irreversible) mutant-selective EGFR TKI for the treatment of EGFRmutant (activating and T790M) NSCLC (42) that was granted breakthrough therapy designation by the FDA in 2014 (74). This decision was based on the initial results of the phase I/II dose-finding trial of rociletinib[CO-1686-008 (TIGER-X), NCT01526928] which had promising and durable antitumour activity in patient with T790M-positive NSCLC following progression on a EGFR TKI (75). The response rate among 46 patients with centrally confirmed T790M-positive tumours was 59\% (95\% CI, $45 \%$ to $73 \%$ ) and $29 \%$ (95\% CI, 8\% to $51 \%$ ) among the 17 patients whose tumours were T790M-negative by central testing. The maximum tolerated dose (MTD) was not reached, hyperglycemia was the only dose-limiting toxicity and a RP2D of $625 \mathrm{mg}$ BID was chosen for future trials (76,77). Two phase II expansion cohorts (NCT01526928) enrolled patients with T790M-positive disease either after progression on their first and only TKI therapy, or after progression on their second or later TKI therapy or chemotherapy. TIGER-X expansion cohorts, combined with data from TIGER-2, were expected to serve as the basis for regulatory approval (77). However, in 2016, following the FDA's decision to not approve the New Drug Application the sponsor announced termination of all ongoing sponsored studies of rociletinib, thus discontinuing rociletinib's development (78).

\section{Nazartinib (EGF816)}

Nazartinib is another irreversible mutant-selective (L858R, Ex19del, and T790M) EGFR inhibitor that specifically targets EGFR-activating mutations arising de novo and upon acquired resistance, while sparing WT EGFR (79). Nazartinib is currently in phase I/II testing in a multicenter, open-label study of EGF816, administered orally in patients with EGFR-mutant NSCLC (NCT02108964) (CEGF816X2101). This study established the RP2D (Phase 1 portion) for nazartinib at $150 \mathrm{mg}$ daily in 2018 (47), and preliminary results of the phase II portion in treatmentnaïve NSCLC patients with activating EGFR mutations (ex19del, L858R) were also presented (80). At cut-off, 45 patients were considered evaluable and among these patients, the overall response was 64\% (29/45; 95\% CI, $49 \%$ to $78 \%$ ) and the disease control rate, $93 \%$. Nazartinib was considered to have tolerable safety profile, frequent AEs (>25\%) regardless of causality were diarrhea (38\%) and maculopapular rash $(31 \%)$, with the latter representing $9 \%$ of grade $3 / 4$ events. Of 17 patients with baseline brain metastases, 9 pts (53\%) showed resolution of these (80).

In a "strategic decision by the company", a phase III study of Nazartinib versus erlotinib/gefinitib (NCT03529084) was withdrawn in 2018, however combination trials with nazartinib are underway (Table 2).

\section{Mavelertinib (PF-06747775)}

Mavelertinib is a selective, third-generation irreversible EGFR TKI being studied in patients with mutated EGFR ex19del or L858R with or without T790M mutation (35). In 2017, the first reports from the ongoing, phase I, first in human study (NCT02349633) in patients with metastatic EGFR mutation-positive NSCLC became available $(49,81)$. Dose escalation with 6 dose levels (25 to $600 \mathrm{mg}$ ) and two expansion cohorts (200 and $300 \mathrm{mg}$ ) was conducted in 44 patients. The RP2D was $200 \mathrm{mg}$ (81). The most common all grade AEs $(\geq 25 \%)$ were: diarrhea $(57 \%)$, rash $(59 \%)$, paronychia (52\%), dermatitis acneiform (34\%), stomatitis 
$(32 \%)$, pruritus $(27 \%)$, dry skin $(25 \%)$, and rhinorrhea $(25 \%)$. There were no grade 4 AEs and preliminary clinical efficacy data is pending (81).

\section{Avitinib (AC0010)}

Avitinib (AC0010) is a third-generation pyrrolopyrimidinebased irreversible EGFR inhibitor which potently inhibits T790M EGFR, but spares EGFR WT (38). The firstin-human dose escalation study of AC0010 in EGFRTKIs resistant (T790M-positive) NSCLC patients (NCT02274337) was published in 2018 (82). Fifty-two patients (45 T790M-positive and 7 T790M-negative) were treated with escalating doses without reaching the MTD. When all evaluated doses and patients (including $\mathrm{n}=7$, T790M-negative) were included, the overall response was $36.5 \%$, but in patients treated with daily doses of $350 \mathrm{mg}$ or higher, the overall response was $50.0 \%$. Common treatment-emergent AEs were diarrhea (75\%), skin rash (48\%), and increased alanine transaminase level (44\%); AEs of grade $\geq 3$ or higher were increased transaminase level $(12 \%)$ and skin rash (4\%). The RP2D was determined to be $300 \mathrm{mg}$ twice daily.

More recently, avitinib was evaluated for blood-brainbarrier penetrability, which was weak (48) (NCT02330367). Sixteen NSCLC patients were included, half (8/16) had brain metastases. The median intracranial PFS of evaluable patients with brain metastases $(n=7)$ was 142 days compared to an overall median PFS of 247 days (95\% CI, 154.8 to 339.2). The cerebrospinal fluid concentration of avitinib was determined to be lower than its $\mathrm{IC}_{50}$ in approximately half of patients, and consequently the calculated blood brain barrier penetration rate was $0.046-0.146 \%$.

An ongoing phase II, single-arm, open-label trial (NCT03300115) in EGFR T790M mutation-positive advanced NSCLC is currently recruiting. This study aims to expand the sample size of patients treated with the RP2D in order to further evaluate the study drug's efficacy (objective response) and safety. This trial is recruiting exclusively in China (see Table 2).

\section{Lazertinib (YH25448/GNS-1480)}

Lazertinib is an oral, potent, irreversible third-generation EGFR TKI that is highly selective for activating EGFR and T790M resistance mutations. In pre-clinical studies, lazertinib induced profound tumour regression in a brain metastasis model with favourable brain/plasma and tumour/ brain area under the concentration-time curve values (39).

An ongoing Korean phase I/II clinical trial for advanced EGFR T790M mutated NSCLC (NCT03046992) n=118), lazertinib demonstrated potent systemic and intracranial activity (83). The dose escalation cohort included 38 patients administered with 20 to $240 \mathrm{mg}$ once daily across 7 dose levels, and 80 patients in the dose expansion cohort were administered 40 to $240 \mathrm{mg}$ (5 dose levels). Of the evaluable patients $(n=110)$ at data cut-off, the objective response was $61 \%$ (95\% CI, $51.8 \%$ to $70.0 \%$ ). The objective response for the T790M-positive patients $(\mathrm{n}=76)$ was $66 \%$ (95\% CI, $56.6 \%$ to $76.0 \%)$, and for the T790M-negative patients $(n=15)$ was $33 \%$. In patients with brain metastases $(n=11)$, the intracranial response was $55 \%$ (95\% CI, $25.1 \%$ to $84.0 \%$ ). The most common treatment emergent AEs were pruritus (24\%), rash (19\%) and decreased appetite (17\%). Recruitment to the dose extension phase is ongoing (Table 2).

\section{Olmutinib (HM61713/BI 1482694)}

Olmutinib was designed as an irreversible third-generation kinase inhibitor active against mutant $E G F R$, including T790M, while sparing WT EGFR (84). NCT01588145 is a phase I/II trial of olmutinib in NSCLC patients with an EGFR mutation. In the phase II part of this trial; 76 patients with T790M-mutant tumours received olmutinib and 71 were evaluable for response (85). Of these, 40 (56\%) had an objective response by investigator review [31 (44\%) confirmed] with a median duration of response of 8.3 months (range 5.6 to $\mathrm{NC}$ ), the disease control rate was $90 \%$ and the median PFS by investigator review was 7.0 months. Olmutinib received breakthrough therapy designation in the United States in 2015 and was approved for use in Korea in 2016 (86). However, our understanding is that in September 2016, South Korea's Ministry of Food and Drug Safety issued a safety letter following two cases of toxic epidermal necrolysis, one of them fatal, and one case of Stevens-Johnson-Syndrome (non-fatal) during the phase II trial of olmutinib, thus halting ongoing studies.

\section{Naquotinib (ASP8273)}

Naquotinib is a third-generation EGFR TKI that targets mutant EGFR, including T790M (87). In a phase I dose-escalation study (NCT02113813), naquotinib was administered to NSCLC patients with disease progression after prior treatment with an EGFR TKI. In total, 110 
patients were treated with naquotinib. Across all doses, in patients with EGFR T790M, the response rate was $30.7 \%$ ( $\mathrm{n}=27 / 88 ; 95 \%$ CI, $19.5 \%$ to $44.5 \%)$, and median PFS was 6.8 months (95\% CI, 5.5 to 10.1 months). Naquotinib was concluded to be well tolerated with demonstrated antitumour activity (87). In the randomized phase III SOLAR trial (NCT02588261), the clinical efficacy and safety of naquotinib was being evaluated compared to erlotinib or gefitinib for the first-line treatment of patients with advanced EGFR-mutant NSCLC, however this trial was terminated upon recommendation by the SOLAR study iDMC, and development of naquotinib was stopped in 2017 (88).

\section{Present and future directions of third-generation EGFR inhibition: combination therapy}

As with other TKIs, patient's tumours inevitably progress whilst on a third-generation EGFR TKI. However, the strategy of combining third-generation EGFR TKI with potentially synergistic agents is being evaluated to overcome resistance and improve efficacy.

\section{Third-generation EGFR TKI in combination with first- and second-generation EGFR TKIs}

Third-generation EGFR TKI inhibitors covalently bind the $\mathrm{C} 797$ residue in the kinase binding site of EGFR, and a mutation at this site (C797S, detected in $20-50 \%$ of cases of acquired resistance to osimertinib) dramatically reduces their potency (89-91). No EGFR TKI to date overcomes triple-mutant (activating mutation/T790M/ C797S) EGFR NSCLC and efforts are underway to prevent the development of this mutation. Pre-clinical studies demonstrated that T790M and C797S mutations occurring in trans retain sensitivity to a combination of first- and third-generation EGFR TKIs (89). C797S, developing in the absence of the T790M mutation, confers resistance to third-generation EGFR TKI while retaining sensitivity to first-generation inhibitors $(89,92,93)$. Thus, erlotinib, and to some extent gefitinib, retain activity against the activating EGFR mutations (ex19del and L858R) and the C797S mutation $(91,94)$. Since osimertinib has demonstrated efficacy in the first-line setting for EGFR activating mutation-positive NSCLC (58), it has been hypothesized that combining first- and third-generation EGFR TKIs may delay the onset of the C797S and T790M resistance mutations, given the efficacy of each agent against these respective mutations. Consequently, combination therapy trials of osimertinib with gefitinib (NCT03122717) and dacomitinib (NCT03810807), and of EGF816 with gefitinib (NCT0329213, NCT03333343) are currently underway (Table 2).

\section{In combination with immunotherapy}

Contrary to work demonstrating improved OS in mouse models of EGFR-driven NSCLC (95), clinical trials examining immune checkpoint inhibitors (ICIs) in NSCLC have consistently failed to show superiority in the ICI arms in EGFR mutation-positive subgroup analyses. A recent review and meta-analysis comparing ICI versus docetaxel in advanced NSCLC (second line setting) involving 3025 patients, confirmed there was no OS advantage in favour of the ICIs for $E G F R$-mutant patients (HR, 1.11; $95 \%$ CI, 0.80 to $1.53 ; \mathrm{P}=0.54$; interaction, $\mathrm{P}=0.005)$, whereas there was reduction in the risk for death in the EGFR WT subgroup (HR, 0.67; 95\% CI, 0.60 to 0.75 ; $\mathrm{P}<0.001$ ) (96).

Durvalumab (anti-PD-L1) was tested in patients with $E G F R$ mutations or $A L K$ rearrangements to establish clinical benefit in the phase II ATLANTIC study (97). The study concluded that a higher proportion of EGFR-/ALKNSCLC patients achieved a response than EGFR+/ALK+ NSCLC, although the activity in patients with EGFR+ NSCLC with $\geq 25 \%$ of tumour cells expressing PD-L1 was encouraging and warranted further investigation.

In a planned paired-biopsy biomarker study from the AURA1 study (98), patients with EGFR mutation-positive NSCLC receiving the EGFR inhibitor osimertinib, had reduced PD-L1 expression and a trend towards increased CD8+ TIL infiltration after therapy, consistent with proinflammatory changes (98). These findings provided the rationale to examine EGFR TKI in combination with ICI (specifically those targeting the PD-1/PD-L1 signaling axis).

The phase Ib TATTON study (NCT02143466) tested osimertinib in combination with durvalumab, savolitinib or selumetinib. The trial included patients with advanced NSCLC who had progressed on prior EGFR-TKI therapy and EGFR-TKI naïve patients with confirmed T790M mutation status. In the durvalumab combination arm, all patients received osimertinib (80 $\mathrm{mg}$ daily) and durvalumab ( 3 or $10 \mathrm{mg} / \mathrm{kg}$ IV q2w). The primary objective was safety and tolerability; secondary objectives included clinical activity. Preliminary data showed that in patients with prior EGFR-TKI therapy, investigator-assessed objective response was $67 \%$ and $21 \%$ in those with T790M-positive and T790M-negative tumours, respectively, and $70 \%$ in 
EGFR-mutant treatment-naïve patients (44). However, this encouraging clinical data was overshadowed by the increased occurrence of ILD events reported with the combination of osimertinib and durvalumab, compared to what would be expected with either drug alone. The combined ILD rate of $38 \%$ [6/23 (26\%) in pre-treated patients, 7/11 (64\%) in TKI-naive patients], with 5 cases of grades $3 / 4$ reported for the combination, was greater than either sole agent. There was no apparent increase in the severity of the ILD.

The CAURAL study (NCT02454933) was a phase III study investigating osimertinib with durvalumab vs. osimertinib monotherapy in patients with EGFR mutation-positive (activating and T790M) advanced NSCLC and disease progression after EGFR-TKI therapy. As with the TATTON trial, it was terminated early due to increased incidence of ILD (99). At termination, 15 patients had been randomly assigned to osimertinib monotherapy and 14 to the combination arm. The most common AEs were diarrhea $[53 \%$ (grade 3 in $6 \%$ of patients)] in the osimertinib arm and rash $[67 \%$ (grade $\geq 3$ in 0 patients)] in the combination arm. One patient randomized to the combination arm reported grade 2 ILD while receiving osimertinib monotherapy (after discontinuing durvalumab therapy after one dose). The objective responses were $80 \%$ in the osimertinib arm and $64 \%$ in the combination arm.

Currently, there are two active phase II clinical trials examining dual-inhibition of ICI and EGFR TKI in EGFR mutation-positive (Ex19del or L858R +/- T790M) NSCLC. PF-06747775 is being combined with avelumab, and in previously treated T790M mutation-positive NSCLC, EGF816 is being combined with nivolumab (Table 2).

\section{In combination with other targeted TKIs or biological agents}

In first-generation TKI-resistant tumors, $M E T$ amplification is a frequent $(5-20 \%)$ mechanism of acquired resistance in pre-clinical and clinical specimens $(25,79,100,101)$. Thus, the study of combined EGFR and MET inhibition in cases of cMET-driven acquired resistance to EGFR TKI is a logical line of inquiry. Savolitinib (c-MET inhibitor) was investigated in combination with osimertinib in the phase Ib TATTON trial with encouraging antitumor activity in patients with NSCLC and MET-driven
EGFR-TKI resistance. At data cut-off ( $\mathrm{n}=45)$, confirmed partial responses were reported in $20 \%(5 / 25)$ of patients previously treated with a third-generation EGFR TKI, and $42 \%(5 / 12)$ and $43 \%(3 / 7)$ in T790M-negative and T790M-positive patients, respectively, without prior third-generation EGFR-TKI exposure (102). Savolitinib is being carried forward into phase II testing with the ongoing SAVANNAH trial (NCT03778229) exploring the combination of savolitinib and osimertinib to overcome MET-driven EGFR TKI resistance following treatment with osimertinib (Table 2). The combination of EGF816 with cMET inhibitor, INC280, is now in phase I/II clinical investigation in patients with advanced EGFR-mutant NSCLC (NCT02335944).

The phase III NEJ026 study combined erlotinib with vascular endothelial growth factor (VEGF) monoclonal antibody inhibitor, bevacizumab, in EGFR-mutated chemotherapy-naïve advanced NSCLC (103). The combination arm demonstrated statistically significant improved PFS and objective response over erlotinib monotherapy, thus supporting the hypothesis of synergism with dual inhibition of EGFR and VEGF pathways. The combination of osimertinib with bevacizumab is being investigated and the first phase I results were reported in 2017, showing that the combination is tolerable (45). Three phase II studies with this drug combination in various lines of treatment are currently ongoing (NCT02803203, NCT03133546, NCT02971501, see Table 2). In addition, a phase II study of osimertinib in combination with the monoclonal antibody VEGF receptor 2 inhibitor, ramucirumab, is expected to begin recruitment in April 2019 (NCT03909334).

Other targeted inhibitors being evaluated in early phase studies in combination with osimertinib include MEK/ MAPK/ERK inhibitor, selumetinib (NCT03392246); AXL inhibitor, DS-1205c (NCT03255083); CDK4/6 inhibitor, G1T38 (NCT03455829); HER-2 targeting antibody-drug conjugate, JAK1 inhibitor (NCT02917993), T-DM1 (NCT03784599); BCL-2 inhibitor, navitoclax (NCT02520778) and anti-EGFR monoclonal antibody, necitumumab (NCT02496663). Combination therapy studies with other third-generation EGFR TKI are also underway and include: MEK1/2 (trametinib with EGF816) (NCT03516214, NCT03333343), CDK4/6 (ribociclib with EGF816, palbociclib with PF-06747775) (NCT03333343, NCT02349633), and RAF pathways (LXH254 with 
EGF816) (NCT03333343) (Table 2).

\section{In combination with other treatments}

Osimertinib is being evaluated in combination with chemotherapy. A phase 1 study of osimertinib with platinum (carboplatin or cisplatin) and etoposide is currently recruiting (NCT03567642), and an ongoing Japanese phase II trial of osimertinib with carboplatin/pemetrexed recently reported safety data (46).

Osimertinib has demonstrated activity in EGFR-mutated NSCLC with brain and leptomeningeal disease $(71,72)$. Stereotactic radiosurgery (SRS) is one of the standard local treatments for patients with brain metastases. However, it is unclear whether adding SRS to osimertinib will improve intracranial disease control in patients with $E G F R$-mutated NSCLC and brain metastases. Osimertinib will therefore be tested alone or in combination with SRS in EGFR-mutated NSCLC with brain metastases, diagnosed de novo or developed while on first-line EGFR TKIs, to assess intracranial disease control (NCT03497767). Osimertinib is also being tested as maintenance therapy following definitive chemo-radiation in locally advanced unresectable EGFR mutation-positive NSCLC (stage III) (NCT03521154).

\section{Conclusions}

The ongoing attempts to identify and target resistance mechanisms to EGFR TKIs in EGFR mutation-positive NSCLC has proved to be a successful strategy, impacting patient efficacy outcomes and quality of life. This is particularly true for the third-generation EGFR TKIs, exemplified by osimertinib which has demonstrated both increased efficacy and less toxicity than the first- and second-generation agents. Osimertinib's impressive efficacy in the CNS has added another treatment modality to radiation for the control of CNS EGFR mutation-positive NSCLC and the oncology community eagerly awaits the OS data from the FLAURA and AURA3 trials. EGFR activating mutation-positive NSCLC is rapidly becoming, for the majority of patients, a chronic disease and the thirdgeneration EGFR TKIs have contributed significantly to this end. Nevertheless, we know that on their own, these agents are not curative and that combination therapy with other agents is a necessary next step in striving for better cancer control. Therefore, there remains much to do!

\section{Acknowledgments}

None.

\section{Footnote}

Conflicts of Interest: GD Goss has received research funding from AstraZeneca. Honoraria from Bristol-Myers Squibb, AstraZeneca, Pfizer and Boehringer Ingelheim. Consulting IO Biotech. NM Andrews Wright has no conflicts of interest to declare.

\section{References}

1. Bray F, Ferlay J, Soerjomataram I, et al. Global cancer statistics 2018: GLOBOCAN estimates of incidence and mortality worldwide for 36 cancers in 185 countries. CA Cancer J Clin 2018;68:394-424.

2. Houston KA, Henley SJ, Li J, et al. Patterns in lung cancer incidence rates and trends by histologic type in the United States, 2004-2009. Lung Cancer 2014;86:22-8.

3. Weinstein IB. CANCER: Enhanced: Addiction to Oncogenes--the Achilles Heal of Cancer. Science 2002;297:63-4.

4. Shi Y, Au JSK, Thongprasert S, et al. A Prospective, Molecular Epidemiology Study of EGFR Mutations in Asian Patients with Advanced Non-Small-Cell Lung Cancer of Adenocarcinoma Histology (PIONEER). J Thorac Oncol 2014;9:154-62.

5. Paez JG, Jänne PA, Lee JC, et al. EGFR mutations in lung cancer: correlation with clinical response to gefitinib therapy. Science 2004;304:1497-500.

6. Lynch TJ, Bell DW, Sordella R, et al. Activating Mutations in the Epidermal Growth Factor Receptor Underlying Responsiveness of Non-Small-Cell Lung Cancer to Gefitinib. N Engl J Med 2004;350:2129-39.

7. Pao W, Miller V, Zakowski M, et al. EGF receptor gene mutations are common in lung cancers from "never smokers" and are associated with sensitivity of tumors to gefitinib and erlotinib. Proc Natl Acad Sci U S A 2004;101:13306-11.

8. Korpanty GJ, Kamel-Reid S, Pintilie M, et al. Lung cancer in never smokers from the Princess Margaret Cancer Centre. Oncotarget 2018;9:22559-70.

9. Burgess AW, Cho HS, Eigenbrot C, et al. An open-andshut case? Recent insights into the activation of EGF/ ErbB receptors. Mol Cell 2003;12:541-52. 
10. Jorissen RN, Walker F, Pouliot N, et al. Epidermal growth factor receptor: Mechanisms of activation and signalling. Exp Cell Res 2003;284:31-53.

11. Ladanyi M, Pao W. Lung adenocarcinoma: guiding EGFR-targeted therapy and beyond. Mod Pathol 2008;21:S16.

12. Sordella R, Bell DW, Haber DA, et al. Gefitinibsensitizing EGFR mutations in lung cancer activate antiapoptotic pathways. Science 2004;305:1163-7.

13. Carey KD, Garton AJ, Romero MS, et al. Kinetic analysis of epidermal growth factor receptor somatic mutant proteins shows increased sensitivity to the epidermal growth factor receptor tyrosine kinase inhibitor, erlotinib. Cancer Res 2006;66:8163-71.

14. Rosell R, Carcereny E, Gervais R, et al. Erlotinib versus standard chemotherapy as first-line treatment for European patients with advanced EGFR mutation-positive non-small-cell lung cancer (EURTAC): a multicentre, open-label, randomised phase 3 trial. Lancet Oncol 2012;13:239-46.

15. Mok TS, Wu YL, Thongprasert S, et al. Gefitinib or carboplatin-paclitaxel in pulmonary adenocarcinoma. $\mathrm{N}$ Engl J Med 2009;361:947-57.

16. Zhou C, Wu YL, Chen G, et al. Erlotinib versus chemotherapy as first-line treatment for patients with advanced EGFR mutation-positive non-small-cell lung cancer (OPTIMAL, CTONG-0802): a multicentre, open-label, randomised, phase 3 study. Lancet Oncol 2011;12:735-42.

17. Mitsudomi T, Morita S, Yatabe Y, et al. Gefitinib versus cisplatin plus docetaxel in patients with non-small-cell lung cancer harbouring mutations of the epidermal growth factor receptor (WJTOG3405): an open label, randomised phase 3 trial. Lancet Oncol 2010;11:121-8.

18. U.S. Food and Drug Administration. FDA approves dacomitinib for metastatic non-small cell lung cancer [Internet] 2018 [cited 2019 Apr 1]. Available online: https://www.fda.gov/drugs/informationondrugs/ approveddrugs/ucm621967.htm

19. U.S. Food and Drug Administration. FDA broadens afatinib indication to previously untreated, metastatic NSCLC with other non-resistant EGFR mutations [Internet] 2018 [cited 2019 Apr 1]. Available online: https://www.fda.gov/drugs/informationondrugs/ approveddrugs/ucm592558.htm

20. Sequist LV, Yang JCH, Yamamoto N, et al. Phase III study of afatinib or cisplatin plus pemetrexed in patients with metastatic lung adenocarcinoma with EGFR mutations. J
Clin Oncol 2013;31:3327-34.

21. Riely GJ, Pao W, Pham D, et al. Clinical course of patients with non-small cell lung cancer and epidermal growth factor receptor exon 19 and exon 21 mutations treated with gefitinib or erlotinib. Clin Cancer Res 2006;12:839-44.

22. Wu YL, Zhou $\mathrm{C}, \mathrm{Hu} \mathrm{CP}$, et al. Afatinib versus cisplatin plus gemcitabine for first-line treatment of Asian patients with advanced non-small-cell lung cancer harbouring EGFR mutations (LUX-Lung 6): an open-label, randomised phase 3 trial. Lancet Oncol 2014;15:213-22.

23. Wu YL, Cheng Y, Zhou X, et al. Dacomitinib versus gefitinib as first-line treatment for patients with EGFRmutation-positive non-small-cell lung cancer (ARCHER 1050): a randomised, open-label, phase 3 trial. Lancet Oncol 2017;18:1454-66.

24. Martinez-Marti A, Navarro A, Felip E. Epidermal growth factor receptor first generation tyrosinekinase inhibitors. Transl Lung Cancer Res 2019. [Epub ahead of print].

25. Yu HA, Arcila ME, Rekhtman N, et al. Analysis of tumor specimens at the time of acquired resistance to EGFR-TKI therapy in 155 patients with EGFR-mutant lung cancers. Clin Cancer Res 2013;19:2240-7.

26. Sequist LV, Waltman BA, Dias-Santagata D, et al. Genotypic and histological evolution of lung cancers acquiring resistance to EGFR inhibitors. Sci Transl Med 2011;3:75ra26.

27. Pao W, Miller VA, Politi KA, et al. Acquired resistance of lung adenocarcinomas to gefitinib or erlotinib is associated with a second mutation in the EGFR kinase domain. PLoS Med 2005;2:e73.

28. Kobayashi S, Boggon TJ, Dayaram T, et al. EGFR mutation and resistance of non-small-cell lung cancer to gefitinib. N Engl J Med 2005;352:786-92.

29. Balak MN, Gong Y, Riely GJ, et al. Novel D761Y and common secondary T790M mutations in epidermal growth factor receptor-mutant lung adenocarcinomas with acquired resistance to kinase inhibitors. Clin Cancer Res 2006;12:6494-501.

30. Kosaka T, Yatabe Y, Endoh H, et al. Analysis of epidermal growth factor receptor gene mutation in patients with nonsmall cell lung cancer and acquired resistance to gefitinib. Clin Cancer Res 2006;12:5764-9.

31. Oxnard GR, Arcila ME, Sima CS, et al. Acquired resistance to EGFR tyrosine kinase inhibitors in EGFRmutant lung cancer: distinct natural history of patients with tumors harboring the T790M mutation. Clin Cancer Res 2011;17:1616-22. 
32. Yun CH, Mengwasser KE, Toms AV, et al. The T790M mutation in EGFR kinase causes drug resistance by increasing the affinity for ATP. Proc Natl Acad Sci U S A 2008;105:2070-5.

33. Cross DAE, Ashton SE, Ghiorghiu S, et al. AZD9291, an irreversible EGFR TKI, overcomes T790M-mediated resistance to EGFR inhibitors in lung cancer. Cancer Discov 2014;4:1046-61.

34. Li D, Ambrogio L, Shimamura T, et al. BIBW2992, an irreversible EGFR/HER2 inhibitor highly effective in preclinical lung cancer models. Oncogene 2008;27:4702-11.

35. Planken S, Behenna DC, Nair SK, et al. Discovery of N-((3R,4R)-4-Fluoro-1-(6-((3-methoxy-1-methyl-1Hpyrazol-4-yl)amino)-9-methyl-9H-purin-2-yl)pyrrolidine3-yl)acrylamide (PF-06747775) through Structure-Based Drug Design: A High Affinity Irreversible Inhibitor Targeting Oncogenic EGFR Mutants. J Med Chem 2017;60:3002-19.

36. Hirano T, Yasuda H, Hamamoto J, et al. Pharmacological and Structural Characterizations of Naquotinib, a Novel Third-Generation EGFR Tyrosine Kinase Inhibitor, in EGFR-Mutated Non-Small Cell Lung Cancer. Mol Cancer Ther 2018;17:740-50.

37. Masuzawa K, Yasuda H, Hamamoto J, et al. Characterization of the efficacies of osimertinib and nazartinib against cells expressing clinically relevant epidermal growth factor receptor mutations. Oncotarget 2017;8:105479-91.

38. Xu X, Mao L, Xu W, et al. AC0010, an Irreversible EGFR Inhibitor Selectively Targeting Mutated EGFR and Overcoming T790M-Induced Resistance in Animal Models and Lung Cancer Patients. Mol Cancer Ther 2016;15:2586-97.

39. Yun J, Hong MH, Kim SY, et al. YH25448, an Irreversible EGFR-TKI with Potent Intracranial Activity in EGFR Mutant Non-Small Cell Lung Cancer. Clin Cancer Res 2019;25:2575-87.

40. Kim D, Kim S, Kim TM, et al. P2.11-010 Phase I study of HM61713, a novel epidermal growth factor receptor (EGFR) mutant selective inhibitor, in non-small cell lung cancer (NSCLC) patients having an activating EGFR mutation but failed to prior EGFR tyrosine kinase inhibitor (TKI) ther. J Thorac Oncol 2013 ;8:S2-1348.

41. Zhou W, Ercan D, Chen L, et al. Novel mutant-selective EGFR kinase inhibitors against EGFR T790M. Nature 2009;462:1070-4.

42. Walter AO, Sjin RTT, Haringsma HJ, et al. Discovery of a Mutant-Selective Covalent Inhibitor of EGFR that Overcomes T790M-Mediated Resistance in NSCLC. Cancer Discov 2013;3:1404-15.

43. Wu YL, Herbst RS, Mann H, et al. ADAURA: Phase III, Double-blind, Randomized Study of Osimertinib Versus Placebo in EGFR Mutation-positive Early-stage NSCLC After Complete Surgical Resection. Clin Lung Cancer 2018;19:e533-6.

44. Ahn MJ, Yang J, Yu H, et al. 136O: Osimertinib combined with durvalumab in EGFR-mutant non-small cell lung cancer: Results from the TATTON phase Ib trial. J Thorac Oncol 2016;11:S115.

45. Yu HA, Hayes SA, Young RJ, et al. A phase 1 study of osimertinib and bevacizumab as initial treatment for patients with EGFR-mutant lung cancers. J Clin Oncol 2017;35:abstr 9033.

46. Okada M, Tanaka K, Asahina H, et al. Safety analysis of an open label, randomized phase 2 study of osimertinib alone versus osimertinib plus carboplatin-pemetrexed for patients with non-small cell lung cancer (NSCLC) that progressed during prior epidermal growth factor receptor (EGFR) tyrosine kinase inhibitor (TKI) therapy and which harbors a T790M mutation of EGFR. J Clin Oncol 2018;36:e21073.

47. Kim DW, Tan DS, Ponce Aix S, et al. Preliminary Phase II results of a multicenter, open-label study of nazartinib (EGF816) in adult patients with treatment-naïve EGFRmutant non-small cell lung cancer (NSCLC). J Clin Oncol 2018;36:abstr 9094.

48. Wang H, Zhang L, Hu P, et al. Penetration of the bloodbrain barrier by avitinib and its control of intra/extracranial disease in non-small cell lung cancer harboring the T790M mutation. Lung Cancer 2018;122:1-6.

49. Husain H, Martins R, Goldberg S, et al. P3.02b-001 Phase 1 Dose Escalation of PF-06747775 (EGFRT790M Inhibitor) in Patients with Advanced EGFRm (Del 19 or L858R+/-T790M) NSCLC. J Thorac Oncol 2017;12:S1185.

50. U.S. Food and Drug Administration. Osimertinib [Internet] 2017 [cited 2019 Mar 12]. Available online: https://www.fda.gov/drugs/informationondrugs/ approveddrugs/ucm549683.htm

51. European Medicines Agency (EMA). Tagrisso: EPAR - Medicine overview [Internet]. Vol. 44. 2018. p. 0-3. Available online: https://www.ema.europa.eu/en/ documents/overview/tagrisso-epar-medicine-overview_ en.pdf

52. Jänne PA, Yang JCH, Kim DW, et al. AZD9291 in EGFR 
inhibitor-resistant non-small-cell lung cancer. N Engl J

Med 2015;372:1689-99.

53. Yang J, Ramalingam SS, Jänne PA, et al. LBA2_ PR: Osimertinib (AZD9291) in pre-treated pts with T790M-positive advanced NSCLC: updated Phase 1 (P1) and pooled Phase 2 (P2) results. J Thorac Oncol 2016;11:S152-S155.

54. Yang JCH, Ahn MJ, Kim DW, et al. Osimertinib in Pretreated T790M-Positive Advanced Non-SmallCell Lung Cancer: AURA Study Phase II Extension Component. J Clin Oncol 2017;35:1288-96.

55. Goss G, Tsai CM, Shepherd FA, et al. Osimertinib for pretreated EGFR Thr790Met-positive advanced nonsmall-cell lung cancer (AURA2): a multicentre, open-label, single-arm, phase 2 study. Lancet Oncol 2016;17:1643-52.

56. Mitsudomi T, Ahn MJ, Bazhenova L, et al. 1348P Overall survival (OS) in patients (pts) with EGFR T790M-positive advanced non-small cell lung cancer (NSCLC) treated with osimertinib: Results from two phase II studies. Ann Oncol 2017;28.

57. Mok TS, Wu YL, Ahn MJ, et al. Osimertinib or PlatinumPemetrexed in EGFR T790M-Positive Lung Cancer. N Engl J Med 2017;376:629-40.

58. Soria JC, Ohe Y, Vansteenkiste J, et al. Osimertinib in Untreated EGFR-Mutated Advanced Non-Small-Cell Lung Cancer. N Engl J Med 2018;378:113-25.

59. U.S. Food and Drug Administration. FDA approves osimertinib for first-line treatment of metastatic NSCLC with most common EGFR mutations [Internet] 2018 [cited 2019 Mar 11]. Available online: https://www. fda.gov/drugs/informationondrugs/approveddrugs/ ucm605113.htm

60. Goss GD, O'Callaghan C, Lorimer I, et al. Gefitinib versus placebo in completely resected non-small-cell lung cancer: results of the NCIC CTG BR19 study. J Clin Oncol 2013;31:3320-6.

61. Kelly K, Altorki NK, Eberhardt WEE, et al. Adjuvant Erlotinib Versus Placebo in Patients With Stage IBIIIA Non-Small-Cell Lung Cancer (RADIANT): A Randomized, Double-Blind, Phase III Trial. J Clin Oncol 2015;33:4007-14.

62. Zhong WZ, Wang Q, Mao WM, et al. Gefitinib versus vinorelbine plus cisplatin as adjuvant treatment for stage II-IIIA (N1-N2) EGFR-mutant NSCLC (ADJUVANT/ CTONG1104): a randomised, open-label, phase 3 study. Lancet Oncol 2018;19:139-48.

63. Ge M, Zhuang Y, Zhou X, et al. High probability and frequency of EGFR mutations in non-small cell lung cancer with brain metastases. J Neurooncol 2017;135:413-8.

64. Schuler M, Wu YL, Hirsh V, et al. First-Line Afatinib versus Chemotherapy in Patients with Non-Small Cell Lung Cancer and Common Epidermal Growth Factor Receptor Gene Mutations and Brain Metastases. J Thorac Oncol 2016;11:380-90.

65. Park SJ, Kim HT, Lee DH, et al. Efficacy of epidermal growth factor receptor tyrosine kinase inhibitors for brain metastasis in non-small cell lung cancer patients harboring either exon 19 or 21 mutation. Lung Cancer 2012;77:556-60.

66. Yu HA, Sima C, Feldman D, et al. Phase 1 study of twice weekly pulse dose and daily low-dose erlotinib as initial treatment for patients with EGFR -mutant lung cancers. Ann Oncol 2017;28:278-84.

67. Gurpide A, Perez-Gracia JL, Lopez-Picazo JM, et al. Activity of gefitinib in central nervous system metastases in patients with non-small-cell lung cancer: two case reports and a review of the literature. Clin Lung Cancer 2005;7:138-40.

68. Hoffknecht P, Tufman A, Wehler T, et al. Efficacy of the irreversible ErbB family blocker afatinib in epidermal growth factor receptor (EGFR) tyrosine kinase inhibitor (TKI)-pretreated non-small-cell lung cancer patients with brain metastases or leptomeningeal disease. J Thorac Oncol 2015;10:156-63.

69. Wu YL, Zhou C, Cheng Y, et al. Erlotinib as second-line treatment in patients with advanced non-small-cell lung cancer and asymptomatic brain metastases: a phase II study (CTONG-0803). Ann Oncol 2013;24:993-9.

70. Goss G, Tsai CM, Shepherd FA, et al. CNS response to osimertinib in patients with T790M-positive advanced NSCLC: pooled data from two phase II trials. Ann Oncol 2018;29:687-93.

71. Wu YL, Ahn MJ, Garassino MC, et al. CNS Efficacy of Osimertinib in Patients With T790M-Positive Advanced Non-Small-Cell Lung Cancer: Data From a Randomized Phase III Trial (AURA3). J Clin Oncol 2018;36:2702-9.

72. Ballard P, Yates JWT, Yang Z, et al. Preclinical Comparison of Osimertinib with Other EGFR-TKIs in EGFR-Mutant NSCLC Brain Metastases Models, and Early Evidence of Clinical Brain Metastases Activity. Clin Cancer Res 2016;22:5130-40.

73. Reungwetwattana T, Nakagawa K, Cho BC, et al. CNS response to osimertinib versus standard epidermal growth factor receptor tyrosine kinase inhibitors in patients with untreated EGFR-mutated advanced non-small-cell lung 
cancer. J Clin Oncol 2018:JCO2018783118. [Epub ahead of print].

74. Dhingra K. Rociletinib: has the TIGER lost a few of its stripes? Ann Oncol 2016;27:1161-4.

75. Sequist LV, Soria JC, Gadgeel SM, et al. 8010: First-inhuman evaluation of CO-1686, an irreversible, highly selective tyrosine kinase inhibitor of mutations of EGFR (activating and T790M). In: 2014 ASCO Annual Meeting 2014.

76. Sequist LV, Soria JC, Goldman JW, et al. Rociletinib in EGFR-mutated non-small-cell lung cancer. N Engl J Med 2015;372:1700-9.

77. Clovis Oncology Inc. Interim Data from Rociletinib (CO1686) Phase $1 / 2$ Study Shows Compelling and Durable Clinical Activity and Progression-free Survival (PFS) in Patients with EGFR-Mutant Non-small Cell Lung Cancer (NSCLC [Internet] 2014 [cited 2019 Mar 12]. Available online: https://ir.clovisoncology.com/investors-andnews/news-releases/press-release-details/2014/InterimData-from-Rociletinib-CO-1686-Phase-12-StudyShows-Compelling-and-Durable-Clinical-Activity-andProgression-free-Survival-PFS-in-Patients-with-EGFRMutant-No

78. Clovis Oncology Inc. Clovis Oncology Announces Q1 2016 Operating Results And Corporate Update [Internet] 2016. Available online: https://ir.clovisoncology. com/investors-and-news/news-releases/press-releasedetails/2016/Clovis-Oncology-Announces-Q1-2016Operating-Results-and-Corporate-Update/default.aspx

79. Jia Y, Juarez J, Li J, et al. EGF816 Exerts Anticancer Effects in Non-Small Cell Lung Cancer by Irreversibly and Selectively Targeting Primary and Acquired Activating Mutations in the EGF Receptor. Cancer Res 2016;76:1591-602.

80. Tan DS, Kim SW, Sequist LV, et al. LBA61 Phase II results for single-agent nazartinib (EGF816) in adult patients (pts) with treatment-naive EGFR-mutant non-small cell lung cancer (NSCLC). Ann Oncol 2018;29:109.

81. Husain H, Martins RG, Goldberg SB, et al. 1358P First-In-Human Phase I Study of PF-06747775, a Third Generation Mutant Selective EGFR Tyrosine Kinase Inhibitor (TKI) in Metastatic EGFR Mutant NSCLC. Ann Oncol 2017;28:v460-v496.

82. Ma Y, Zheng X, Zhao H, et al. First-in-Human Phase I Study of AC0010, a Mutant-Selective EGFR Inhibitor in Non-Small Cell Lung Cancer: Safety, Efficacy, and Potential Mechanism of Resistance. J Thorac Oncol 2018;13:968-77.
83. Cho BC, Han JY, Kim SW, et al. YH25448, a 3rd generation EGFR-TKI, in patients with EGFR-TKIresistant NSCLC: Phase I/II study results. J Clin Oncol 2018;36:abstr 9033.

84. Lee KO, Cha MY, Kim M, et al. Abstract LB-100: Discovery of HM61713 as an orally available and mutant EGFR selective inhibitor. In: Proceedings of the 105th Annual Meeting of the American Association for Cancer Research; 2014 Apr 5-9; San Diego, CA. Philadelphia (PA): AACR; Cancer Res 2014;74:Abstract nr LB-100. doi:10.1158/1538-7445.AM2014-LB-100.

85. Park K, Lee JS, Lee KH, et al. BI 1482694 (HM61713), an EGFR mutant-specific inhibitor, in T790M+ NSCLC: Efficacy and safety at the RP2D. J Clin Oncol 2016;34:abstr 9055.

86. Kim ES. Olmutinib: First Global Approval. Drugs 2016;76:1153-7.

87. Yu HA, Spira A, Horn L, et al. A Phase I, Dose Escalation Study of Oral ASP8273 in Patients with Non-small Cell Lung Cancers with Epidermal Growth Factor Receptor Mutations. Clin Cancer Res 2017;23:7467-73.

88. Astellas Pharma Inc. Astellas Announces Decision to Discontinue ASP8273 Treatment Arm and Close Randomization for Clinical Study Protocol 8273-CL0302 [Internet] 2017 [cited 2019 Mar 29]. Available online: https://newsroom.astellas.us/2017-05-10Astellas-Announces-Decision-to-Discontinue-ASP8273Treatment-and-Close-Randomization-for-Clinical-StudyProtocol-8273-CL-0302

89. Niederst MJ, Hu H, Mulvey HE, et al. The Allelic Context of the C797S Mutation Acquired upon Treatment with Third-Generation EGFR Inhibitors Impacts Sensitivity to Subsequent Treatment Strategies. Clin Cancer Res 2015;21:3924-33.

90. Oxnard GR, Hu Y, Mileham KF, et al. Assessment of Resistance Mechanisms and Clinical Implications in Patients With EGFR T790M-Positive Lung Cancer and Acquired Resistance to Osimertinib. JAMA Oncol 2018;4:1527-34.

91. Nishino M, Suda K, Kobayashi Y, et al. Effects of secondary EGFR mutations on resistance against upfront osimertinib in cells with EGFR-activating mutations in vitro. Lung Cancer 2018;126:149-55.

92. Uchibori K, Inase N, Araki M, et al. Brigatinib combined with anti-EGFR antibody overcomes osimertinib resistance in EGFR-mutated non-small-cell lung cancer. Nat Commun 2017;8:14768.

93. Ercan D, Choi HG, Yun CH, et al. EGFR Mutations 
and Resistance to Irreversible Pyrimidine-Based EGFR Inhibitors. Clin Cancer Res 2015;21:3913-23.

94. Yang Z, Yang N, Ou Q, et al. Investigating Novel Resistance Mechanisms to Third-Generation EGFR Tyrosine Kinase Inhibitor Osimertinib in Non-Small Cell Lung Cancer Patients. Clin Cancer Res 2018;24:3097-107.

95. Akbay EA, Koyama S, Carretero J, et al. Activation of the PD-1 Pathway Contributes to Immune Escape in EGFRDriven Lung Tumors. Cancer Discov 2013;3:1355-63.

96. Lee CK, Man J, Lord S, et al. Clinical and Molecular Characteristics Associated With Survival Among Patients Treated With Checkpoint Inhibitors for Advanced NonSmall Cell Lung Carcinoma: A Systematic Review and Meta-analysis. JAMA Oncol 2018;4:210-6.

97. Garassino MC, Cho BC, Kim JH, et al. Durvalumab as third-line or later treatment for advanced non-small-cell lung cancer (ATLANTIC): an open-label, single-arm, phase 2 study. Lancet Oncol 2018;19:521-36.

98. Thress KS, Jacobs V, Angell HK, et al. Modulation of Biomarker Expression by Osimertinib: Results of the Paired Tumor Biopsy Cohorts of the AURA Phase I Trial. J Thorac Oncol 2017;12:1588-94.

Cite this article as: Andrews Wright NM, Goss GD. Thirdgeneration epidermal growth factor receptor tyrosine kinase inhibitors for the treatment of non-small cell lung cancer. Transl Lung Cancer Res 2019;8(Suppl 3):S247-S264. doi: 10.21037/tlcr.2019.06.01
99. Chih-Hsin Yang J, Shepherd FA, Kim DW, et al. Osimertinib Plus Durvalumab versus Osimertinib Monotherapy in EGFR T790M-Positive NSCLC following Previous EGFR TKI Therapy: CAURAL Brief Report. J Thorac Oncol 2019;14:933-9.

100. Bean J, Brennan C, Shih JY, et al. MET amplification occurs with or without T790M mutations in EGFR mutant lung tumors with acquired resistance to gefitinib or erlotinib. Proc Natl Acad Sci 2007;104:20932-7.

101. Engelman JA, Zejnullahu K, Mitsudomi T, et al. MET Amplification Leads to Gefitinib Resistance in Lung Cancer by Activating ERBB3 Signaling. Science 2007;316:1039-43.

102.Ahn M, Han J, Sequist L, et al. OA 09.03 TATTON Ph Ib Expansion Cohort: Osimertinib plus Savolitinib for Pts with EGFR-Mutant MET-Amplified NSCLC after Progression on Prior EGFR-TKI. J Thorac Oncol 2017;12:S1768.

103. Furuya N, Fukuhara T, Saito H, et al. Phase III study comparing bevacizumab plus erlotinib to erlotinib in patients with untreated NSCLC harboring activating EGFR mutations: NEJ026. J Clin Oncol 2018;36:abstr 9006. 